University of Nebraska - Lincoln

DigitalCommons@University of Nebraska - Lincoln

H. W. Manter Laboratory Library Materials

3-1916

Gongylonema in the Role of a Human Parasite

Henry Baldwin Ward

University of Illinois

Follow this and additional works at: https://digitalcommons.unl.edu/manterlibrary

Part of the Parasitology Commons

Ward, Henry Baldwin, "Gongylonema in the Role of a Human Parasite" (1916). H. W. Manter Laboratory Library Materials. 11.

https://digitalcommons.unl.edu/manterlibrary/11

This Article is brought to you for free and open access by DigitalCommons@University of Nebraska - Lincoln. It has been accepted for inclusion in H. W. Manter Laboratory Library Materials by an authorized administrator of DigitalCommons@University of Nebraska - Lincoln. 


\section{GONGYLONEMA IN THE ROLE OF A HUMAN PARASITE *}

Henry B. Ward

Through the kindness of Dean Charles E. Brookover of the University of Arkansas Medical Department, Little Rock, I received recently a specimen of a nematode which has not heretofore been recorded as a human parasite. The worm was removed from the lip of a girl. The conditions surrounding the case are reported as follows by the attending physician, Dr. Robert Lee Covington of Jefferson, Ark., to whom I am indebted not only for the case history cited here, but also for replies to several inquiries on the matter necessary to perfect the record for publication. Dr. Covington's report is as follows :

Miss -, 16 years old. I was called to see her September 3. Found her suffering with considerable digestive disturbance, vomiting continuously for two or three hours; temperature $101.5 \mathrm{~F}$. She felt chilly. I administered calomel followed with castor oil. Later I gave her full doses of turpentine and castor oil. The fever would come and go and for this I gave quinin. She improved some; later the fever abated entirely, but some digestive disturbance still persisted. She was very anemic and irritable. September 12 I dismissed her.

I was again called October 1 . She wanted me to see what that was running around under the skin of her lip, as she expressed it. I thought it was pure imagination. She said she could see it by looking in the mirror; she said it looked like a worm, and at times she could feel it leave her lips and go back as far as the fauces. I examined the lower lip where she said it had stopped. I discovered the outline of what looked like a worm about three quarters of an inch in length and about the size of a No. 60 sewing thread; it was just beneath the mucous membrane. I inserted a needle under it and pulled out a little of one end, but before I could grasp it, it got away, moving back near the corner of the mouth. There I ran the needle under it midway between the ends and pulled upward, bringing a small loop through the mucous membrane. It held on so tight that the ends on each side of the needle cut their way out.

Up to this time she was extremely anemic and very cross and irritable, but after the removal of the worm she rapidly improved, her disposition changed, and now she is not like the same girl. She seems to be sound and well at this date.

Jan. 26, 1916.

Dr. Robert LeE Covington, Jefferson, Ark.

In response to specific questions Dr. Covington stated that the worm moved up and down in the tissues three or four times, extending its migrations from the lips at least as far back as the fauces. It was actually seen by the patient three times and she reported it positively

* Contributions from the Zoological Laboratory of the University of Illinois, No. 59. 
to her father the day before its removal. It could be discerned clearly enough to tell that it was a worm; in color it was a little lighter than the mucous membrane. During its movements the worm was definitely sensible to the patient only when it approached the skin and it was not seen or felt in this organ anywhere except on the inside of the lips. It was seen only inside the mouth through the thin mucous membrane of that cavity and so far as known did not approach the external skin save at the inner border of the lower lip.

From this record one may safely conclude that it migrated to and fro through the loose connective tissue beneath the oral mucosa and endeavored to move up into the firmer derma only when it approached the lips. From the fact that it evaded the surgeon for a time, one can see that the movement was free and active.

Subsequently. Dr. Covington wrote regarding the patient: "She has lived here all her life, has not traveled in any other country. . . . Sanitary conditions are not just what they ought to be. They get drinking water from a well that is very shallow and fills up to the top when it rains heavily."

On preliminary examination it appeared that the specimen had suffered somewhat in the handling incidental to its forcible removal, and was not in such histological condition that much could be said definitely regarding its internal structure.

Under a dissecting lens the specimen (Fig. 1) is seen to be a nematode worm, light brown in color, semitranslucent, and loosely coiled, though both ends are nearly straight. The worm measures $42.1 \mathrm{~mm}$. in total length and is of nearly equal diameter throughout, tapering only a little near the two ends which terminate rather abruptly.

The anterior end appears to taper more toward the bluntly round tip and for a space of $1.4 \mathrm{~mm}$. from the end the surface is ornamented by various cuticular outgrowths like scales or tubercles. These are arranged in somewhat definite fashion (Fig. 2). A cuticular ridge extends along the lateral line of the body starting at a point about $0.25 \mathrm{~mm}$. from the extreme anterior tip and running back about 1.5 $\mathrm{mm}$. In the anterior region this ridge is slightly irregular but nearly equal in height at all points; further back it is divided by deep indentations into long ovals. At the place where it starts the diameter of the body is about $0.1 \mathrm{~mm}$. and at its posterior end the body has increased in diameter to $0.19 \mathrm{~mm}$.

In the submedian lines are rows of scales, plates, or tubercles that start just behind the front end of the ridge just described and extend backwards only about $1.1 \mathrm{~mm}$. in definite and regular order. These tubercles stand in a linear series so close together that they are practically continuous even though separated from each other by a distinct boundary line. They vary in form and size but on the average 
are nearly square in profile and measure $0.022 \mathrm{~mm}$. in height and 0.025 to 0.3 or rarely $0.045 \mathrm{~mm}$. in length. In front of this close-set series and of the cuticular ridge one finds a number of isolated cuticular bosses which in part line up with the ridge or the series and in part do not. Between the ridge and the series are a few isolated scales. These are irregular, detached, and on the average larger than the tubercles in the regular series.

The anterior tip of the body possesses a small infundibuliform crown surrounding the mouth which may represent a group of lips with some papillae. From the orifice a capilliform esophagus extends posteriad and disappears from view behind the anterior tip of the cuticular ridge. In the mid-ventral line about $0.6 \mathrm{~mm}$. from the anterior tip is a peculiar papilla that probably surrounds the excretory pore. The location of the end of the esophagus is difficult to determine precisely; it appears to be about $7.5 \mathrm{~mm}$. from the anterior end. Here the diameter of the body is $0.23 \mathrm{~mm}$.; a measure which is manntained with only slight variations from 0.22 to $0.24 \mathrm{~mm}$. approximately, throughout the entire length until the caudal region is attained.

The vulva is a ventral, slightly prominent pore with raised lips, located $2.15 \mathrm{~mm}$. from the posterior tip of the body. Even behind it the body retains its uniform caliber of approximately $0.23 \mathrm{~mm}$. until close before the anus or about $0.25 \mathrm{~mm}$. from the exterior tip. This region is a little damaged by handling, but shows distinctly a slight concavity on the dorsal surface making the bluntly rounded posterior tip of the body turn a bit upwards. At the anal orifice the body measures $0.09 \mathrm{~mm}$. in diameter, which is evidently somewhat less than normal owing to the injury already noted. The taper begins only a short distance anteriad to the anus, and if the specimen had been uninjured, would have been regular apparently from that point to the rounded tip. There is certainly no abrupt change in diameter either before or behind the anus.

There can be no doubt that this specimen belongs to the genus Gongylonema in the family of the Filariidae. Gongylonema is a nematode peculiar in habit in that it forms a sinuous gallery in the mucous epithelium of the esophagus. The worm lies in this tunnel with the anterior region alone projecting from it. With a single exception all species are found in mammals. The body is very long and thread-like, showing a slight taper toward both extremities. The characteristic feature of this genus is the presence on the anterior region of a considerable number of scales or tubercles which are elevated thickenings of the external cuticula only. These differ in size, number, and arrangement in different species. Cuticular folds stand out from the surface along the median or lateral lines in the 
anterior region, and form conspicuous features in the external aspect of the worm. These also vary in number, form, and extent in various species. The vulva is located near the posterior end, and its precise position as well as the form and size of the tip of the tail are valuable in determining the species of female specimens.

Two species of Gongylonema are common to domestic animals in the United States, and fall under suspicion as possible occasional parasites of man. These are G. scutatum and G. pulchrum. Of $G$. ingluvicola Ransom from chickens it need only be said that the structure of the adult is too dissimilar to allow of the surmise that this specimen is an erratic individual of that species. But the other two are much alike in structure and are abundant in some parts of this country, if not in most regions; they are also both very similar to the specimen under consideration.

G. scutatum was recently described with some care by Ransom (1911) who declares that it is very common in this country and can be found in a large percentage of cattle and sheep slaughtered at abattoirs.

G. pulchrum is known as a parasite of the hog in Europe, and has been found also in North Africa by Seurat (1912). It does not seem to have been reported in print from the United States previous to this year when it was briefly mentioned by Ransom and Hall (1916) in connection with the discussion of experiments on the life history of G. scutatum. They have found it to be frequent in the vicinity of Washington, D. C., and it doubtless occurs abundantly in the pig in other regions as well. Dr. B. H. Ransom was good enough to send me specimens for comparison. These came from the collections of the Bureau of Animal Industry and were taken from a hog at Bethesda, Md., in January, 1914.

These two species are very similar, and in the present case it is impossible to assert positively which one is the specimen under consideration. It agrees in length with $G$. pulchrum and as nearly as can be ascertained also in the character of the female genital organs of which a comparative study has been published by Seurat (1912). The caudal tip is also slightly concave on the dorsum as has been described in that species. However, this specimen is a trifle over ordinary length for G. pulchrum, although it has not yet reached full sexual maturity. But the genital pore is salient, although not notably so, a feature which is said to be characteristic of $G$. pulchrum though wanting in $G$. scutatum. On the whole, I am inclined to determine the specimen from man as G. pulchrum. The common ascarid of man, the stomach worm, $A$. lumbricoides, is also a parasitc of the pig in which it occurs abundantly in all parts of the country. 
The specimen under consideration manifested a habit that so far as known is not characteristic of the genus to which it must be assigned. It was engaged in active migrations through the subdermal connective tissue, and the patient was conscious of the fact. It had approached near enough to the surface to be seen and correctly diagnosed in form, and had wandered away into deeper tissues. The worm may have been thus active over a period of a month or less. It moved through the connective tissue rapidly enough to render its capture and removal a matter of skill and dexterity. Such performances are not reported in other accounts of the genus, which as already noted is found in the mucosa of the esophagus in its normal host, and has not been collected from other organs or regions. The presence of the chicken species in the wall of the crop is not a real departure from this general habit for it occurs there in the mucous lining according to Ransom's report. It is, of course, possible that these forms regularly inhabit the subdermal connective tissue during a period of their life cycle and appear in the esophageal mucosa at the time of sexual maturity; or such an occurrence may be exceptional but actual in the normal host also. In that event it would readily escape notice under usual conditions. There is no basis for deciding whether such wanderings are usual but unnoted heretofore in the normal host, so rare in it as to have evaded observation thus far, or peculiar to the human host or to this particular case.

The habit recalls very strikingly the wandering through subdermal tissues of the African eyeworm, Filaria loa, which has received its name from its frequent appearance in the subcutaneous connective tissues near the eyeball. It is also well known to occur in the same tissues elsewhere in the body. Among the cases on record are a few which report its removal from the lip or near the same, but it occurs habitually near the external skin and is not reported from the vicinity of the mucosa. Yet it is not at all impossible that in some instance where no careful examination was made a specimen of Gongylonema has been interpreted as the loa. The length of the specimen reported here and its appearance agree in general with the loa, and while it is not quite so heavy nor so opaque, the two might readily be confused if no careful microscopical examination-were made; all the more so since the loa is the only nematode which has been known to move about in subdermal tissues and that striking habit would have been taken to indicate the type of parasite at hand.

There are other records of parasitic nematodes from man in this country that should be brought briefly under consideration in connection with the case in hand. In 1850 Dr. Joseph Leidy of Philadelphia 
described a human parasite as Filaria hominis oris from a specimen in the collection of the Philadelphia Academy labeled "obtained from the mouth of a child."

This account of Leidy has always been difficult to interpret. His conjecture that it was a young Dracunculus or Medina worm has been generally rejected and other suggestions are not entirely satisfactory. The location suggests that the specimen may have been a Gongylonema, not the species here reported for that is much too short, but $G$. scutatum of cattle and sheep which is of the right dimensions. Leidy was a very accurate observer and it is improbable that he would have overlooked the cuticular tubercles on the anterior end if such had been present. The condition of the specimen might have been such as to prevent the diagnosis of these structures, but on the whole the case can hardly be assigned to Gongylonema even tentatively.

The source of the infection in the case at hand can not be positively ascertained and yet recent studies suggest a very probable explanation. Thanks to the careful work of Ransom and Hall which has extended over several years it is now known that the larvae of $G$. scutatum occur in various species of dung beetles and that they have been raised experimentally not only in these but also in croton bugs. Furthermore, eggs of a Gongylonema, most probably G. pulchrum from the esophagus of a hog, were fed to croton bugs and at the close of a month embryos were found encysted in the final stage and ready for transmission.

In the present case it is easy to see how an infected insect, very likely a croton bug, might have been ingested whole, or some fragments of it included by accident in meal, flour, milk, or other materials used in cooking. Such sanitary mishaps are very common with poorly prepared food, and thus the infection of the human host would have been achieved. The sanitary conditions noted in the clinical history of the case favor such an occurrence.

The duration of the infection can be estimated as at least a month if the clinical symptoms stand in any connection with the parasite. No data have been found to show the rate of development of these worms in the final host but if one can infer safely from other nematodes it is likely that this specimen was in the human host more than a month and that the symptoms did not manifest themselves until it had attained a certain measure of growth. These symptoms were so definite and terminated so promptly with the removal of the parasite that etiologic significance can hardly be denied to the worm.

\section{SUMMARY}

A specimen of Gongylonema, probably G. pulchrum, has been recovered from man. This species is normally a parasite of the pig. 


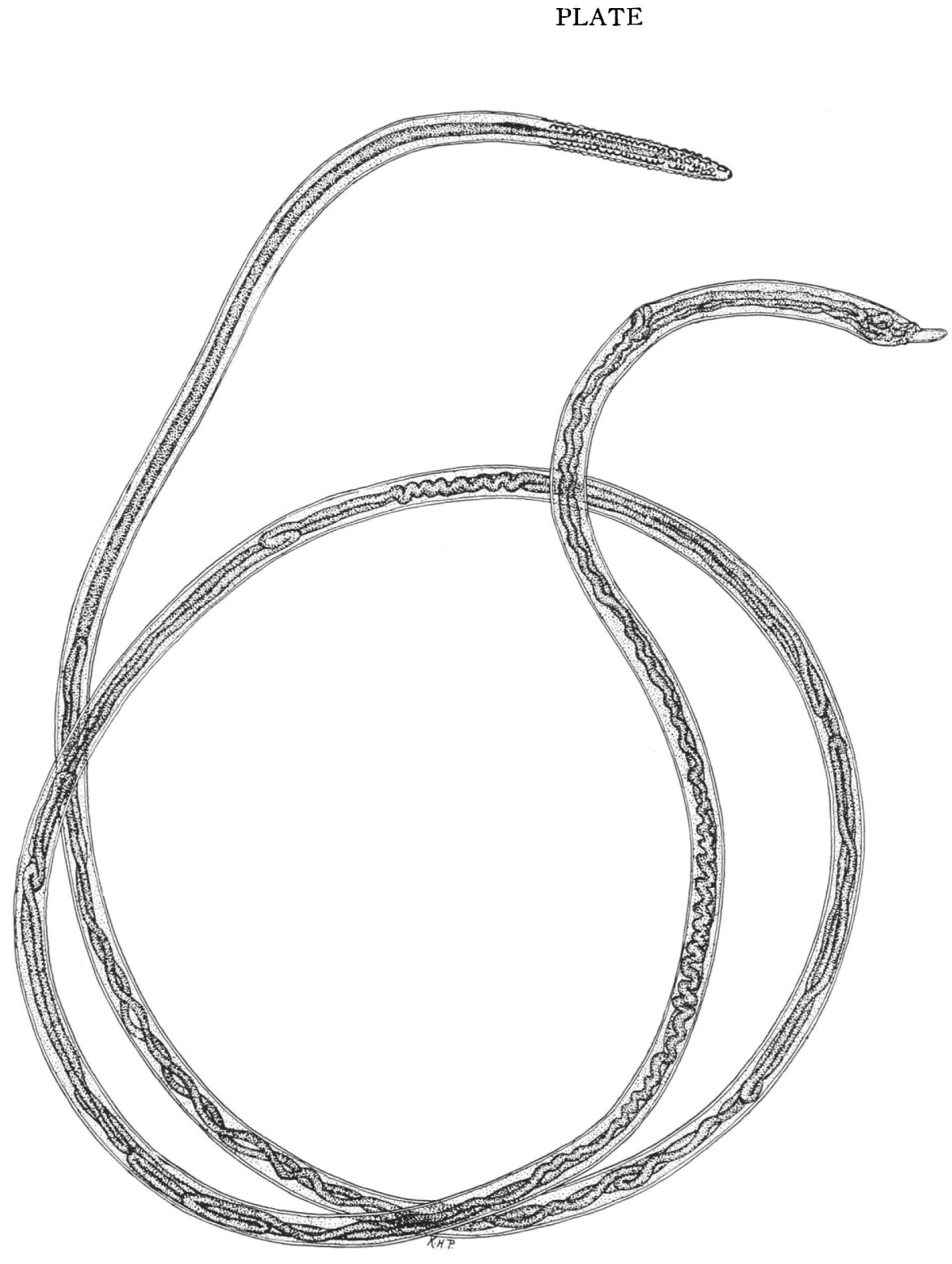

Fig. 1

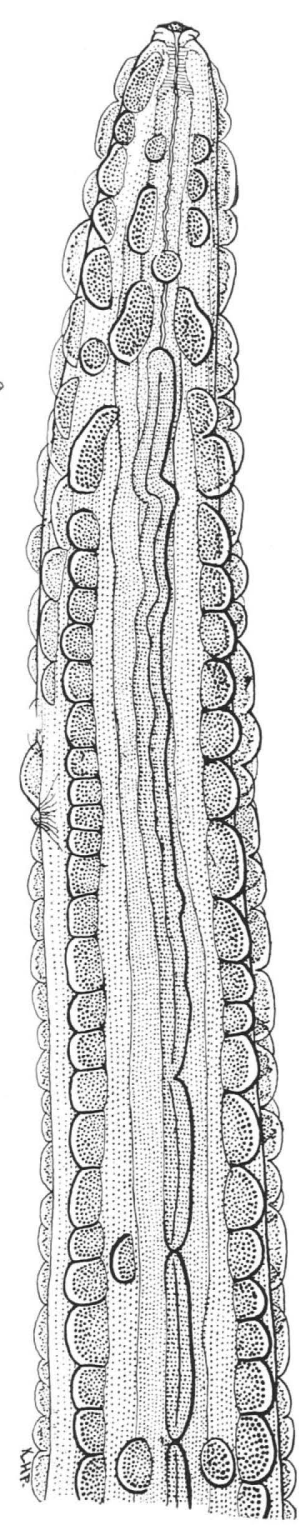

Fig. 2

EXPLANATION OF FIGURES

Fig. 1.-Gongylonema (pulchrum?) from human host. Camera drawing. X 15.

Fig. 2.-Anterior end of same specimen. Camera drawing. X 140. 
Infection of the human host was brought about probably by the ingestion of larvae in the infective stage which had developed in some insect. Very likely the croton bug, known by experiment to be able to serve as intermediate host for this species, was the source of the infection which might readily occur by accident.

The presence of the parasite was accompanied by clinical symptoms indicating marked digestive and nervous disturbances, associated with anemia. These symptoms disappeared with the removal of the worm.

The parasite displayed a tendency to wander through the submucosal connective tissue from the lips to the throat.

\section{Papers Cited}

Leidy, Jos. 1850. Description of Three Filariae. Proc. Acad. Nat. Sci, Phila., 5: 117-8.

Neumann, L. G. 1894. Sur le genre Gongylonema Molin. Mém. Soc. Zool. France, $7: 463-473 ; 4$ figures.

Ransom, B. H. 1904. A New Nematode (Gongylonema ingluvicola) Parasitic in the Crop of Chickens. Bur. An. Ind., Circ. 64. 1911. The Nematodes Parasitic in the Alimentary Tract of Cattle, Sheep, and Other Ruminants. Bur. An. Ind., Bull. 127.

Ransom, B. H., and Hall, M. C. 1916. The Life History of Gongylonema scutatum. J. Parasitol., 2: 80-86.

Seurat, L. G. 1912. Sur l'appareil génital femelle des Gongylonemes. C. R. Soc. Biol., 73:276-9; 5 figures. 